\title{
Recurrent Narratives Around the COVID-19 Crisis in Social Networks: A Case Study Analysis on Facebook
}

\author{
Venetia Papa \\ Theodora A. Maniou \\ University of Cyprus (Cyprus)
}

In recent years, social networks have played a significant role during major crisis events as citizens use these networks to seek information, discuss and share personal news stories, while interacting with other users regarding issues related to the perceived crisis. As a result, news content posted on social networks is of crucial importance since it can affect public opinion in various ways. The aim of this study is to assess dominant narratives generated through users' reactions towards news content posted on Facebook so as to examine the role of Facebook during the global crisis of COVID-19. Drawing from different aspects of crisis communication theory and audience-centered studies, this work seeks to investigate the constructed meanings related to this crisis and interpret users' understanding of news content posted on social networks. Content analysis is employed as a means to evaluate Facebook's potential in (re)defining users' narratives regarding issues related to COVID-19.

Keywords: COVID-19, Facebook, crisis, users' narratives, news stories.

\footnotetext{
7 OVID-19 was identified in December 2019 in China as a new and unknown virus, which rapidly spread out globally and was declared a pandemic on March 11, 2020 by the World Health Organization (WHO). As with every crisis, both traditional and new media had a significant role to play towards the dissemination of information. Whereas the role of traditional media has been assessed in the past during health crises (i.e., Maniou, 2015), the role of new media - and especially social networks - has not thus far been investigated in a global outbreak of such an extended scale. More importantly, during a period of increased need for rapid and accurate information, the use of social networks by the traditional media as platforms for time-efficient information dissemination remains a thus far understudied realm.
} 
The aim of this study is to assess recurrent narratives generated through users' reactions towards news content posted on Facebook so as to examine the role of the platform in question during the global crisis of COVID-19. Drawing from different aspects of crisis communication theory and audience-centered studies, this work seeks to identify these recurrent narratives related to the crisis and interpret users' understanding of news content posted on social networks. Content analysis is employed as a means to evaluate Facebook's potential in (re)defining users' narratives regarding issues related to COVID-19.

\section{SOCIAL NETWORKS IN TIMES OF GLOBAL CRISIS: CRISIS COMMUNICATION AND USERS' PERCEPTIONS}

One of the major transformations in late-modern societies is the interactional potential of ICTs, which can create the conditions for greater citizens' participation and engagement. Dahlgren (2009) points out the relevance of two distinct phenomena: individuation and dispersion of shared unifying cultural frameworks. Individuation refers to a decrease in the feeling of social belonging, which mainly ascribes to a feeling of personal autonomy. This goes hand in hand with the pluralisation and "nichification" of society in terms of media patterns, cultural interests, lifestyles and the fostering of social orientations (Pongolini, Lundin, and Svensson, 2011).

Central to this optimistic outlook are two elements: the online participatory patterns allowing greater civic interaction among citizens, and the online civic resources providing meaningful civic participation and engagement (Dahlgren, 2009). One prominent idea is the premise that social networks offer a wide array of opportunities for citizen participation, which reinforces the notion of "engaged and interactive citizens". As Hermes (2006: 304) argues, such practices,

involve a variety of knowledge and activities, include emotion, sensation and experience and deliver, in varying degrees, a state of being informed and of commitment to larger communities.

Several empirical studies confirm a positive correlation between the frequency of social media use and citizens participation (Valenzuela, 2013). Facebook, for example, has been declared very effective in reaching and engaging masses of interested individuals by providing a space for high-quality political and other types of discussions (Kushin and Kitchener, 2009). Overall, social networks seem to be able to increase citizens' participation both online and offline, and, in this way, offer alternative patterns of engagement (Zúñiga, Nakwon-Jung, and Valenzuela, 2012). While these networks were initially praised for providing a platform for public discourse, more recent studies indicated that users' comments on social media often contain high levels of negative emotions, incivility, and hostile rhetoric (Ceron, 2015; Muddiman and Stroud, 2017; Humprecht, Hellmueller, and Lischka, 2020).

Other scholars discuss the importance of these new configurations and the impact of social networks as a set of cultural factors. They are able to affect the 
formation of public opinion on the basis of disseminating analyses posted within their public spaces (Tchubykalo, Manfredi-Sánchez, and Sánchez-Giménez, 2019) while producing civic resources (e.g. economic, technical, and discursive) readily available for users, and generating channels for civic engagement and participation, which can in turn engender new forms of civic identities (Papa, 2017).

The power of social networks in disseminating news stories while creating social narratives seems undeniable. Several studies have focused on the "communicative how" of narrative telling's, the ways stories are told and shared within online environments and their significance (Georgakopoulou, 2007). Social networks allow users to "develop relationships by means of two socionarrative practices - telling (mainly in the form of posting) and sharing-" (Massa and Simeoni, 2017). Narrative is flexible and often combines a variety "of voices in a single event or become a single event told by multiple storytellers who have the common aim to inform, to entertain, to persuade, to build communal bonds, to strengthen relationships, to preserve self or to heal" (Jaworksi and Coupland, 2008: 25). Narrative within social networks can be considered as a collection of stories afforded by the technological device and shared among users creating a performative domain of social action (Massa and Simeoni, 2017). In this light, commenting COVID-19 stories online can bring together multiple user-tellers not only for sharing their personal stories but also for shaping, changing and understanding the stories of others during this pandemic crisis.

The role of social networks in global health crises needs to be further elaborated; after all, the COVID-19 pandemic is the first phenomenon of such nature to affect the globe after the introduction of social networks. So far, documented research indicates that during crises, social media can provide a new platform for online word-of-mouth communication, working as an informal channel through which information regarding products, services, organizations or individuals is conveyed, shared, and processed (Austin, Fisher-Liu, and Jin, 2012). Their use can change drastically in times of crisis, as issues emerging online can be more unpredictable, taking dramatic turns and proliferating more rapidly than issues emerging offline; thus, social media allow for more immediate responses and interactive communication during crises (Coombs, 2008).

Aspects of infotainment seem to play a significant role towards this direction. While infotainment can be a wide field of research, for the purposes of this study we define infotainment as the journalistic practice that encompasses and employs, among others, personalization, features of personal life, emotions, morbidity, and sensationalism (Mellado, 2015; Photiou et al., 2017; Photiou et al., 2019).

On the other hand, crisis management through social networks can prove to be an arduous task, as the swift (mis)information profusion requires sources of information (e.g., organisations involved) to launch a dynamic social media presence so as to present their version of the story (DiStaso, Vafeiadis, and Amaral, 2015). Guidry et al. (2017) argue that social media messaging may be most effective when it is based on the strategic use of risk-communication principles such as solution-based messaging, incorporation of visual imagery, and acknowl- 
14 edgement of public fears and concerns. In addition, not all social networking platforms perform the same functions for their users, neither do they present identical features and characteristics. For example, Facebook, Twitter and Instagram operate under different perspectives, with Facebook being thus far the most influential and broad one.

Regarding users' perceptions of crisis situations, one of the central arguments in appraisal theory is that people cope with stressful situations differently (Lazarus, 1991) and their emotional manifestations in different situations are varied (Duhachek, 2005). Coombs' (1998) situational crisis communication (SCCT) theory is based on an audience-centered approach for understanding how stakeholders react in crisis situations by surveying their attribution of crisis responsibility and assessment of crisis types. Jin, Pang, and Cameron (2007) further argue that an alternative, emotion-based perspective should be integrated into the audience-centered approach in order to understand how stakeholders are likely to experience, feel, and evaluate crisis situations (see also, Jin, 2010). Audiences seek out social media during crises because they provide an unfiltered, up-to-date line of communication (Procopio and Procopio, 2007) and unique information unobtainable elsewhere (Sutton, Palen, and Shklovski, 2008). In addition, audiences use social media for emotional support and recovery from crises (Stephens and Malone, 2009; Austin, Fisher-Liu, and Jin, 2012; Gerbaudo, 2012).

This study seeks to investigate whether all these functions adhere not to the overall content posted on social networks during a crisis situation, but specifically to distinct news content produced by traditional news organisations. Several studies so far have shown that traditional components of print, television and radio, in many ways constitute a poor vehicle for the communication of scientifically accurate information about health —especially during a crisis situation — as they seem prone to sensationalism, sins of omission and even sheer inaccuracy (Leask, Hooker, and King, 2010; Maniou, 2015). In this light, investigating the dissemination of news content, produced by traditional media, through social networks, can lead to a better understanding of recurrent narratives regarding global health crises, as generated and shared in these networks. Yet to emerge is the significance of narratives propagated through Facebook and the cultural meanings these stories convey during the pandemic crisis.

\section{RQs, Sample and Methodology}

The study initiated from the following Research Questions:

- RQ1. Which are the recurrent narratives that emerge from news content posted on Facebook regarding the global health crisis of COVID-19?

- RQ2. How are these narratives constitutive of the meanings of the current crisis?

The sample comprises of news media articles and users' comments attached to 300 news articles, posted on the official Facebook page of the top five in reader- 
ship newspapers worldwide. ${ }^{1}$ The sample was drawn from the official Facebook pages of each medium selected in order to capture a general picture of users' comments and avoid biases induced by website-specific characteristics. The media outlets selected for this analysis have an active Facebook page, are publishing news articles written by professional journalists, and contain open and visible comment sections for all users. The sample of news outlets included five newspapers with a global audience: The New York Times, The Guardian, Le Monde, Washington Post and Daily Mail. It has to be noted that all five are rooted in the global North; as such, their target audience mainly comprises of citizens in respective countries. In order to select a sample of the groups that were returned by the search engine, five criteria were applied. Namely, Facebook pages were selected if they (a) had more than 50 members or likes, (b) were public, (c) contained a written description of the news media outlets, (d) contained more than 50 posts and comments, and (e) were active during the periods selected for data collection. The final sample consisted of 5 Facebook pages $^{2}$ related to the news media outlets.

An important task before the collection of Facebook posts and comments was the delimitation of COVID-19 events in time (dates) and space (countries of interest) (see Koopmans and Rucht, 2002). This was accomplished by mapping the major global outbreak trajectory of COVID-19 in order to select the major events between December 2019 and April 2020. These were selected following three basic criteria: (a) the calendar of events published by the World Health Organization (WHO), (b) the number of Facebook posts, and (c) media coverage. Table 1 presents the major events during which the posts and comments were collected. The total posts analyzed were 3000, attached to 300 articles posted by the news media outlets in question.

\section{Table 1. Major outbreak events during COVID-19}

31/12/2019: COVID-19 has broken out in Wuhan, China (WHO has been informed)

30/01/2020: WHO declares the outbreak of COVID-19 as public disease

11/02/2020: WHO names the disease as COVID-19

8/03/2020: Italy places 16 million people in quarantine. Two days later, the quarantine is expanded to cover the entire country

11/03/2020: WHO declares the COVID-19 outbreak a pandemic

1 To sample the news media outlets for the content analysis, we used Alexa.com's rankings of the 5 most visited news outlets worldwide at the time this study was conducted (April 2020).

2 The sample of news outlets included the Facebook pages of the five international newspapers, as listed here: <https://www.facebook.com/nytimes/,https://www.facebook.com/ theguardian/,https://www.facebook.com/lemonde.fr/,https://www.facebook.com/washingtonpost/, https://www.facebook.com/DailyMail/>. 
12/03/2020: Global stock markets crash

14/03/2020:Spain and France go into lockdown

17/03/2020:European leaders close the EU's external and Schengen borders in an effort to control COVID-19

20/03/2020: The worldwide death toll from COVID-19 surpasses 10,000

26/03/2020: Global COVID-19 cases reach 500,000, with 23,000 deaths. USA surpasses China and Italy in number of known COVID-19 cases, with more than 1,000 deaths

2/04/2020: Lock-down in almost all EU countries and USA. Cases and deaths are particularly high in Italy, Spain, UK, France and the USA.

5/4/2020: The USA is declared as the country with the most infected cases $(311,637)$ ahead of Spain

$(126,168)$. Confirmed deaths: Italy: 15,362 . Spain: 11,947 . USA: 8,454. France: 7,560.

Source: Own elaboration.

The posts were collected only between the above-mentioned dates, excluding other content found online. Although the data do not cover COVID-19's entire trajectory, the sample corresponds with the major outbreak events related to COVID-19. The collection of posts employed a data mining technique based on the software "exportcomments", an open-source analysis software used primarily for network analysis, discovery and exploration of particular social media spaces. "Exportcomments" has a modular architecture, which allows for the extraction and importation of Facebook data from specific dates and specific Facebook pages onto excel sheets.

The posts were analyzed via thematic content analysis (Ahuvia, 2001). The analysis focused on identifying nodal points - the core signs within COVID-19 users' discourses that are crucial for indicating the meanings in the discourse-; these can be understood as the key concepts or vocabulary of the discourse. Discourses interpellate subjects, addressing them and providing them with subject positions. The ultimate goal of the analysis is the exploration of the new meanings narratives can produce within the specific socio-cultural context in which they occur (Georgakopoulou, 2007). As such, narrative is seen as the prime site for the exploration of the communicative how of narrative telling 's (idem) during a specific event — such as the COVID-19 pandemic crisis—. Through repeated readings, recurrent lines narratives were identified. Extracts for the analysis were selected rigorously, fulfilling the criteria regarding content, length, variety, structure, clear argumentation, ideas and meaning.

\section{FINDINGS AND ANALYSIS}

The narratives of Facebook comments are related not only to users' comments but also to the evolution of the COVID-19 crisis in different countries. The three categories emerging from the analysis are the following: the first category corresponds to "infotainment" - type information, the second refers to raised awareness around COVID-19-related issues, while the third category suggests a more 
emotional construction regarding the pandemic. We endeavored to present posts from all the pages analyzed based on the common meanings attributed to the different categories rather than to disperse the posts among the categories. This choice is justified by the fact that no distinct discursive elements were differentiated in the pages examined. After continuous readings of the material, we concluded that the collected posts from all pages constitute a single volume of material that could be analyzed based on the different lines of argumentation contained therein. The predominant recurrent narratives emerging from the analysis are the following: the one of citizens' in opposition to the elites during the COVID-19 pandemic (1198 posts) and the narrative of personalised, infotainment stories used as a "way out" of the pandemic crisis (703 posts). The secondary narratives are the following: the one referring to the lock-down as a suddenly imposed calamity among EU and USA citizens (599 posts), the construction of emotional narratives among "victims" of COVID-19 and the struggle against the "invisible enemy" (252 posts), and the social media as an interactive and flexible vehicle for creating supportive actions (248 posts).

Table 2. Number of comments linked to each narrative

\begin{tabular}{|c|c|c|}
\hline & Comments & $\%$ of total sample \\
\hline $\begin{array}{l}\text { 1.Personalised, infotainment stories as a 'way out' of the pandemic } \\
\text { crisis }\end{array}$ & 703 & $23,43 \%$ \\
\hline $\begin{array}{l}\text { 2. Raised awareness around the impact of COVID-19: } \\
\text { 2.1.The lock-down as a suddenly imposed calamity among EU and USA } \\
\text { citizens }\end{array}$ & 599 & $19,96 \%$ \\
\hline 2.2. Citizens in opposition to the elites during the COVID-19 pandemic & 1198 & $39,93 \%$ \\
\hline $\begin{array}{l}\text { 3. Emotions as a unifying discursive attribute of the pandemic crisis: } \\
\text { 3.1. Construction of emotional narratives among "victims" of COVID-19 } \\
\text { and the struggle against the "invisible enemy" }\end{array}$ & 252 & $8,42 \%$ \\
\hline $\begin{array}{l}\text { 3.2. Social media as an interactive and flexible vehicle for creating } \\
\text { supportive actions }\end{array}$ & 248 & $8,26 \%$ \\
\hline
\end{tabular}

Source: Own elaboration.

\section{Personalised, Infotainment Stories Used As a 'Way Out' From the PANDEMic Crisis}

The first category is identified as entertaining information with an emphasis on humor, sarcasm and irony. The focus here is on the communication style of the stories shared rather than the meaning or the content itself. The first narrative of argumentation reveals that users - through memes, gifs and pokesdisseminated more personalized and emotionally oriented messages as a way of shedding negative feelings off during the COVID-19 pandemic. "Making fun" of COVID-19 seems to be a negative outcome related to social overload. The use of Facebook can evoke a feeling of flow, which is characterized primarily by strong 
18 emotions, high arousal and "fun". Humor can be seen as a way to shift perspective from the stressful and exhausting information overload provoked as users continuously browse news. Thus, humor is understood as a way of distancing themselves from the pandemic as a "problem" and immediate "threat", reducing the paralyzing feelings of fear and helplessness.

Brexit is more harmful and more contagious than the coronavirus! (The Guardian, $31 / 01 / 20)$.

I ate a sweet and sour chicken ready meal from Bejams once and today I'm feeling a bit under the weather. Is this it am I going to die.remember me to my children (The New York Times, 31/01/20).

In addition, humor used in Facebook comments served to convey xenophobic and racist messages. Humor can be seen as a unifying element among users and operates in relation to two pillars: (a) the Chinese - as the "bad other", the "enemy" - and the ones who spread the dangerous virus, and (b) the political elites who seem to be ignorant. Through sarcastic and ironic posts users seem to demonstrate their disagreement and disapproval of governmental policies to keep the airspace with China open. Through humor, they implicitly call governments into question and challenge the existing situation. Chinese people are depicted with strong, negative language, often using an ironic tone such as: "stay away from the outsiders of china town", or "the Chinese parasites who split everywhere and eat weird animals". Thus, by means of such reactions the Chinese are constructed as the negative actors whose behavior conforms to a hidden economic agenda, which has now been revealed to all other citizens. They often qualify COVID-19 as the "mistake" of China that is now being spread around Europe. This is evident through the deployment of the narrative "superpower dictators". There is also an indirect attribution of blame to the Chinese government, which is qualified as "oppressive", "immoral", "selfish", "uncivilized" and "negligent".

Not Xenophobia. It's China Chinese's \& CCP's fault for this China version Chernobyl. They hidden the truth \& situation, caught those speak \& warn the truth, let the potential infected travel to everywhere at the beginning, swept out most of the surgical mask from the rest of the world \& fucked other Oriental faces up (The Guardian, 11/2/20).

It's egoistic, irresponsible, bad intentioned, $\mathrm{n}$ all those Chinese who knew about the risk and came from that chin-Chun-lin city where this Virus is and move outside, they should be arrested and charged with crimes against the humanity (The Guardian, 11/2/20).

Ultimately, users tend to argue around the need to protect their "nation" from the "enemies", presented as "outsiders", "liars" and "irresponsible". Avoiding and expulsing the Chinese is thus represented as a liberating solution that would allow citizens to protect themselves from COVID-19. Users in this category are making use of emotions and sensationalism through personalized messages in 
order to stimulate the senses of other audiences and trigger an emotional response by highlighting the unusual, unexpected or spectacular humoristic aspects of the news stories (Grabe, Shuhua, and Brooke, 2001).

\section{Raised Awareness Around the Impact of COVID-19}

The second line of argumentation is expressed in three diverse ways, each of them emphasizing different yet non-conflicting elements.

\section{The Lock-Down As a Suddenly Imposed Calamity among EU and USA Citizens} The first line of argumentation focuses on the way a general lockdown is perceived as an illegitimate decision, and introduces violation as an illegitimate loss of collective liberties and rights. What is contended is its sudden imposition to citizens all over the world and COVID-19 is represented in terms of a calamity that violated fundamental rights regarding free movement. Its unexpectedness is deployed as a way to foreground the severity of the consequences it has provoked. This is represented through various metaphors, which serve to make descriptions more vivid and create solid, tangible images of calamities in order to strengthen their effects on citizens. These metaphors also imply the lack of alternative choices for most citizens following WHO's recommendations.

Trading freedom for the illusion of safety is ALWAYS a moronic plan. ALWAYS (The Guardian, 13/3/20).

He's right, the police have no business doing this, this is the definition of totalitarianism. A hard-right government giving itself sweeping powers, is not one that will give those powers back when this "crisis" is over. Is this Police State control or genuine care for the community? (The Guardian, 30/3/20).

The argumentation underlying the construction of this specific narrative as a calamity is defended by resorting to emotion and intense images, which enforce a specific negative representation of the healthcare system, the police, and the authorities. It is generally expressed as a form of collective fear, panic, and anger resulting from the pandemic. Blame is attributed to both national and international actors through the argument that all the political systems are corrupt. Consequently, governments are often represented as "responsible" for the collapse of national health systems.

They are useless but so are Labour, Lib Dems in fact the whole of parliament plus the house of lords with their barons and baronesses... nothing new I have been round the block many times for voting for parties and it is load of tripe they are all the same when you think of it. Coronavirus is here, they need to act (The Washington Post, 11/2/20).

London is a waste of power. We need devolved power. Imagine our counties working together so solve this instead of 3 weeks delay from Boris Johnson the utter waste of space. We should have closed the border (The Daily Mail, 5/4/20). 
A second line of argumentation is that the situation in question is represented in a rather individualized way, with emphasis on the individual moral and economic resulting from the lockdown. There seems to exist a line of argumentation which is founded upon those marginalized: the unemployed, the homeless, the artists, the immigrants and the ones often qualified as "excluded" from the economic measures designed by governments. The loss of individual wealth is represented in dramatic terms as a domino process affecting citizens in terms of salary cuts.

\begin{abstract}
Maybe they're hoping for lots of death as a way to fix their austerity measures. They don't have to worry about the people they're underfunding because these people are sick and elderly because they'll be dead (The Guardian, 12/3/20).
\end{abstract}

The economic measures implemented as a remedy for the pandemic crisis are understood as revealing the already existing social inequalities among citizens. They are often rejected, not simply as unfair but also as useless for those affected by the situation. This behavior undermines the effectiveness of the proposed measures. The emphasis is on portraying the economic and social measures as part of an experiment taking place all over the world; hence, the effectiveness of the process is still to be tested after the end of the pandemic. Strong criticism is expressed vis $a$ vis the inequality represented in economic measures. Blame is attributed to the political elites, which are considered incompetent, since they were incapable of taking corrective measures in advance in order to protect their citizens.

\title{
Citizens in Opposition to the Elites During the COVID-19 Pandemic
}

The second category refers to the political elites and political parties around the world. This narrative is founded on the notion of blame, itself deriving from users' knowledge that major events during the viral outbreak could have been controlled or even prevented by the ruling elites (Austin, Fisher-Liu, and Jin, 2012). Most users are favoring direct attack as their strategy against the political elites. Thus, the reasoning upon which the opposition is built refers to the inadequacies of the elites to pursue their assigned tasks, such as conducting mass testing, or their support of big corporations instead of the citizens in need. Starting with the political elites, the main representations are: (a) unreliable vis a vis their electoral promises to support the healthcare system; (b) traitors, since they did not support people's needs and opted to serve other interests (corporations, airlines, banks, pharmaceutical companies); (c) powerless, since they failed to stand up and face the health crisis.

I have no doubt health systems the world over are overwhelmed and there in lies the problem... not in the virus itself... it's all got to do with politicians anxious to be re-elected handling "as best as they can" a crisis of their own making, and all they can come up is "controlled-terror in small doses" (The Daily Mail, 5/4/20).

The analysis further reveals that self-identification of citizens commenting in these groups often goes beyond the local (national) context, evoking a rather transnational community (Hermes, 2006). Facebook posts demonstrate the openness of the category even in periods of crisis, which is expanded not only to na- 
tional subjects but also to all citizens, who feel neglected by the political system in general, and the healthcare system in particular. Such a community is created around a common feeling of disappointment, and represents a form of solidarity. This narrative speaks of a violation of human rights and inequality, often expressed as illegitimate loss of material goods resulting from the lockdown. Victims are represented as the citizens who personally experience injustice, a reference that demonstrates the large scale of illegitimacy. Illegitimacy affects a rather transnational community of citizens, alluded to by such slogans as "citizens beyond borders", "we are all affected" and "no one is excluded from the enemy". Some subjects claim that the injustice of this political decision is perceived as a feeling of frustration and exclusion from politics.

\section{Emotions As a Unifying Discursive Attribute of the Pandemic CRISIS}

The third line of argumentation seems to be founded on citizens' emotions and feelings. The analysis reveals that these news media pages allowed citizens to construct resonant emotional conversations and transform their personal frustration and anxiety to a collective one, shared among all citizens affected by the crisis. Emotional narratives seem to transform sentiments of collectivity to feelings of togetherness during the current pandemic. The emotional construct here is seen as a relationship of solidarity and empathy between those affected and those infected by COVID-19. As a result, the Facebook page facilitates bonding and mutual support among citizens expressed through lexical choices such as "let's fight together the invisible enemy", "we need to save ourselves and others" or "solidarity is the only way to tackle the invisible enemy". This tendency follows two major themes.

\section{Construction of Emotional Narratives among "Victims" of COVID-19 and the Struggle Against the "Invisible Enemy"}

The first theme refers to users who use the narration of their personal stories and everyday experiences around COVID-19 in order to construct mutual feelings of solidarity and thus create a collective health consciousness. One of the major arguments is that although the "invisible enemy" violates users' freedom, there are many people dying and suffering from the situation. To this end, citizens need to continue the struggle and fight for their health due to the pandemic's severity. In contrast to the aforementioned, the emphasis of this opinion is on such users' unifying principle, namely, the notion of victimhood. The victims are often referred to as those mostly "touched from COVID-19", "the most vulnerable", the "blacks", the "elderly". The pandemic crisis — conceptualized as the condition which rendered them victims - is further qualified as unprecedented.

I feel able to comment as it is thought that I have COVID-19 - no one will know unless I have immunity testing down the line-. I am doing ok on day 11 and think I'm at the end of it nearly. To the point the Maths is needed to gauge what is needed to fight it be it troops, ventilators, masks but that's all (Le Monde, 5/4/20). 
Personal feelings and stories circulated in the various news outlets' Facebook pages are referring mostly to the personal health situation of citizens as a result of the pandemic. In order to provide evidence for this argumentation, a list of personal stories is presented - although this is not a detailed account- Nonetheless, the use of personal statements is intended to add objectivity to their accounts. Users deploy repetition and vivid description such as "health victims" and "economic victims". The dominant discursive emotions are anxiety and sadness, which are experienced by users with guilt and shame. Users are sharing stories in order to express either an irrevocable, tangible or intangible loss, or both (Lazarus, 1991). This particular loss is related to grief and users seem to be desperate and in need for relief and comfort. The feeling of sadness is observed through a high amount of shared news stories around COVID-19. The emotional experiences shared online can create affective relations. Given that, effective crisis communication depends on how well political authorities can manage and address these types of citizens' anxieties.

\section{Social Media As an Interactive and Flexible Vehicle for Creating Supportive Actions}

The second line of argumentation that is projected is the ability of the technological tool to reinforce reciprocity and interactivity among users, thus establishing solidarity and initiating action for those who are in need. Specifically, the categories mentioned are: the elderly, the immigrants and the homeless. This position is specified as a way of mobilizing or taking action for those in need. Some actions expressed in these Facebook pages include the donation of money and the delivery of food. Users tend to evaluate these actions positively. This is primarily because such pages provide opportunities for direct communication among citizens around the world and their own personal networks of friends, which lays the foundations for the creation of a community around a shared feeling of togetherness. This form of online social networking facilitates the transformation of citizens into active participants during the COVID-19 crisis, by allowing them to spread action-related information quickly and effectively.

\section{CONCLUSION}

The focus of this study has been the analysis of the recurrent narratives associated with the COVID-19 pandemic. The analysis has focused on untangling the constructed meanings and their interpretations as these relate to the crisis. The analysis highlights the importance of understanding the mediation of crisis situations by social media and monitoring their effective use (in line with Austin, Fisher-Liu, and Jin, 2012). In this case, we aimed to explore these narratives using an audience approach in crisis communication through social networks.

The first narrative reveals that a high personalization of user's news stories through sarcasm and irony is favored over knowledge and information around the pandemic. Its manifestations may range from the use of irony, humor and sarcasm in news stories to the deployment of negative xenophobic messages. 
This form of narrative is common for social media use in crisis communication; however, applied research shows that users who share their stories online utilize social media as an "homeostasis utility" - to maintain an equilibrium or balance in the user's life (Goldsmith and Horowitz, 2006) - . To this end, our findings suggest that users seemed uncertain of how to cope with the existent threat of the virus and often chose avoidance or escape from the current situation as an action tendency. The use of humor and sarcasm, as a way to foster a community against the "enemy", facilitates the construction of social and relational identities (Romero and Pescosolido, 2008). However, news stories provided and shared via Facebook can be qualified as "oversimplified", causing a negative effect on the narration of the crisis, rather than producing uniform discursive narratives. Consequently, the "bad" quality of news stories and information circulating in the public sphere might discourage citizens in engaging and participating online in such issues.

The second category refers to the discursive meaning constructed around a sentiment of raised awareness related to the impact of COVID-19, which is clearly marked as a consistent and uniform narrative demonstrating a heterogeneity among users' discourses. Users' comments acquire a rather negative overtone towards political elites and political authorities who are systematically blamed for the current situation. From the public's point of view, the central issue of the crisis is always goal-relevance. Our findings suggest that social media can be seen as the space per se where users form an "online community" with shared interests and goals around the pandemic crisis. This finding relativizes perceptions regarding Facebook's intrinsic capacity to enable the creation of online communities with shared motivations, especially during crisis, that transcend given boundaries; instead, its affordances can equally enable fragmentation instead of unity, and activate mechanisms of exclusion instead of inclusion. The online data seem to refer to two modes of communicative practices usually established on social media: "instrumental" and "expressive". This is an analytic dichotomy, which first emerged within political science while studying voters' motivational patterns, and may therefore be used during highly mediated-communication processes. Users' discourses hint towards a more instrumental discourse, where those involved are interested in the actual social outcomes and consequences of the pandemic. On the contrary, expressive modes of reflection identify as beneficial a more long-term process of mobilization of public opinion around health care issues. Through these types of narration, citizens tend to gain a sense of empowerment during the crisis, and therefore feel that expressing their opinions online pertains to their duties as "informed citizens". The findings seem to coincide with an emerging discourse often found in social media that combines the discursive frames (e.g. claims) and communication style of right-wing populism in Europe. Therefore, further empirical research is needed to shed light in this particular narrative during the COVID-19 pandemic crisis.

The third category emerging from the analysis is centered on emotions, which often take the form of a unifying, discursive element. This category is apparent through a symbolic construction of the crisis around emotions, feelings and personal stories, which allow for a feeling of togetherness to be established. The 
technical affordances offered by Facebook could easily become the instruments of emotional and personal narration, which in turn can reinforce bonds among users. Exchanging experiences and stories online can create the conditions for "emotional health communities" with similar concerns and motivations to thrive (Gerbaudo, 2012). These emotions seem to construct new layers of meaning around COVID-19 by strengthening shared attitudes and norms among users. The instrumentalization of fear, anxiety, anger and sadness (Lazarus, 1991) is a way for citizens to face an immediate, concrete and overwhelming, albeit unknown danger. This analysis reveals that citizens during the current pandemic crisis are making use of their multiple subject-positions, daily experiences and roles, in order to create a sense of mutual support and solidarity, making the sharing of emotional content online ever more significant. Sharing emotionally charged stories online requires motivation and incentive and is not as easy as clicking on the "like" button. This kind of practice can potentially promote the subjective side of civic empowerment and offer a sense of civic agency through online practices significant for engagement and participation in discursive or informational circulation during crises (Papa, 2017). Practices of this nature can be established as civic resources and motivate citizens towards creating and disseminating civic knowledge necessary in periods of crisis. We may also expect the rise of a new, "civic vernacular", or at least the further maturation of the conditions essential for the accomplishment of civic agency (Papacharissi, 2010).

This study provides significant insights into social media narratives in times of pandemic crises, by examining both the content of such narratives and meaning communicated and introduces valuable analytical tools, necessary for a more in-depth analysis of audiences' viewpoints and motivations. Future research could shed light on the current new media landscape and its offline implications in the formation of public opinion, and social and political identities around such issues.

Venetia Papa (Papa.venia@gmail.com) is a lecturer in Journalism and Media Studies at the Department of Social \& Political Sciences, University of Cyprus. She has received her Ph.D. in Communication and Internet Studies from the Cyprus University of Technology (CUT) and her MA and BA from the University of Nice Sophia Antipolis, in Fran-

Theodora A. Maniou (Maniou.theodora@ ucy.ac.cy) is a lecturer in Journalism at the Department of Social \& Political Sciences, University of Cyprus. She holds a Ph.D \& a ce. Her current research interests lie in the fields of new and alternative media, internet politics, online communities, and social movements. She is currently the coordinator of the research lab DAT-ACT at the University of Cyprus working on the emerging big data ecology through innovative and advanced methodological tools.

BA in Journalism (Department of Journalism \& MC, Aristotle University of Thessaloniki, Greece), and an MA in Communication's Policy Studies (City, University of London, UK). 
Her area of specialization focuses on journalism practice, new forms of journalism, broadcast journalism in television, and multimedia journalism. She has worked as a journalist for several years and is a member of the International Federation of Journalists, the European Federation of Journalists and the Journalistic Union of Macedonia-Thrace (Greece).

\section{References}

Ahuvia, A. (2001). "Traditional, Interpretive, and Reception Based Content Analyses: Improving the Ability of Content Analysis to Address Issues of Pragmatic and Theoretical Concern". Social Indicators Research, 54(2), pp. 139-172.

Austin, L.; Fisher-Liu, B., and Jin, Y. (2012). "How Audiences Seek Out Crisis Information: Exploring the Social-Mediated Crisis Communication Model". Journal of Applied Communication Research, 40(2), pp. 188-207. DOI: $<10.1080 / 00909882.2012 .654498>$.

Ceron, A. (2015). "Internet, News, and Political Trust: The Difference Between Social Media and Online Media Outlets". Journal of Computer-Mediated Communication, 20(5), pp. 487-503. DOI: <10.1111/jcc4.12129>.

Coombs, W. T. (1998). "An Analytic Framework for Crisis Situations: Better Responses from a Better Understanding of the Situation". Journal of Public Relations Research, 10, pp. 177191.

-. (2008). "Crisis Communication and Social Media". Essential Knowledge Project, Institute for Public Relations. Available at: <http:// www.instituteforpr.org/essential_knowledge/ detail/crisis_communication_and_social_ media>. Accessed 22 April 2020.

Dahlgren, P. (2006). "Doing Citizenship: The Cultural Origins of Civic Agency in the Public Sphere". European Journal of Cultural Studies, 9(3), pp. 267-286.

-. (2009). Media and Political Engagement: Citizens, Communication, and Democracy. Cambridge: Cambridge University Press.
DiStaso, M. W.; Vafeiadis, M., and Amaral, C. (2015). "Managing a Health Crisis on Facebook: How the Response Strategies of Apology, Sympathy, and Information Influence Public Relations". Public Relations Review, 41(2), pp. 222-231.

Duhachek, A. (2005). "Coping: A Multidimensional, Hierarchical Framework of Responses to Stressful Consumption Episodes". Journal of Consumer Research, 32(1), pp. 41-53.

Georgakopoulou, A. (2007). Small Stories, Interaction and Identities. Amsterdam/Philadelphia: John Benjamins.

Gerbaudo, P. (2012). Tweets and the Streets. London: Pluto Press.

Goldsmith, R. and Horowitz, D. (2006). "Measuring Motivations for Online Opinion Seeking". Journal of Interactive Advertising, 6(2), pp. 3-14.

Grabe, M. E.; Shuhua, Z., and Brooke, B. (2001). "Explicating Sensationalism in Television News: Content and the Bells and Whistles of Form". Journal of Broadcasting and Electronic Media, 45(4), pp. 635-655. DOI: <10.1207/ s15506878jobem4504_6>.

Guidry, J.; Jin, Y.; Orr, A. C.; Messner, M., and Meganck, S. (2017). "Ebola on Instagram and Twitter: How Health Organizations Address the Health Crisis in Their Social Media Engagement". Public Relations Review, 43(3), pp. 477-486. DOI: <10.1016/ j.pubrev.2017.04.009>.

Hermes, J. (2006). "Citizenship in the Age of the Internet". European Journal of Communication, 21(3), pp. 295-309. 
Humprecht, E.; Hellmueller, L., and Lischka, J. A. (2020). "Hostile Emotions in News Comments: A Cross-National Analysis of Facebook Discussions". Social Media+Society, 6(1). DOI: $<10.1177 / 2056305120912481>$.

Jaworski, A. and Coupland, N. (2008). The Discourse Reader. London: Routledge.

Jin, Y.; Pang, A., and Cameron, G. T. (2007). "Integrated Crisis Mapping: Towards a Publics-Based, Emotion Driven Conceptualization in Crisis Communication". Sphera Publica, 7, pp. 81-96.

Jin, Y. (2010). "Making Sense Sensibly in Crisis Communication: How Publics' Crisis Appraisals Influence Their Negative Emotions, Coping Strategy Preferences, and Crisis Response Acceptance". Communication Research, 37(4), pp. 522-552. DOI: $<10.1177 / 0093650210368256>$.

Koopmans, R. and Rucht., D. (2002). "Protest Event Analysis". In: Klandermans, B. and Staggneborg, S. (eds). Methods of Social Movement Research. Minneapolis: University of Minnesota Press, pp. 231-59.

Kushin, M. J. and Kitchener, K. (2009). "Getting Political on Social Network Sites: Exploring Online Political Discourse on Facebook". First Monday, 14(11).

Lazarus, R. S. (1991). Emotion and Adaptation. New York: Oxford University Press.

Leask, J.; Hooker, C., and King, C. (2010). "Media Coverage of Health Issues and How To Work More Effectively with Journalists: A Qualitative Study". BioMEd Central Public Health, 10 (535). DOI: <10.1186/1471-245810-535>.

Maniou, T. (2015). "Reporting on Health Issues: Communicating Public Health Through the Press in Time of Crisis". The International Journal of Communication and Health, 5, pp. 36-43.

Massa, E. and Simeoni, V. (2017). "Posting As a Form of Storytelling: The Sociolinguistic Analysis of a Sample of Pregnancy Narratives on Facebook". Signs and Society, 5(1), pp. 124153.
Mellado, C. (2015). "Professional Roles in News Content: Six Dimensions of Journalistic Role Performance". Journalism Studies, 16(4), pp. 596-614. DOI: $<10.1080 / 1461670 X .2014 .922276>$.

Muddiman, A. and Stroud, N. J. (2017). "News Values, Cognitive Biases, and Partisan Incivility in Comment Sections". Journal of Communication, 67, pp.586-609. DOI: $<10.1111 /$ jcom.12312>.

Palen, L. [et al.] (2007). "Crisis Informatics: Studying Crisis in a Networked World". Proceedings of the Third International Conference on E-Social Science, pp. 7-9. Available at: DOI: $<$ http://citeseerx.ist.psu.edu/viewdoc/downl oad?doi=10.1.1.113.5750\&rep=rep1\&type $=p$ df>. Accessed 17 April 2020.

Papa, V. (2017). “To Activists: Please Post and Share Your Story': Renewing Understandings on Civic Participation and the Role of Facebook in the Indignados Movement". European Journal of Communication, 32(6), pp. 583-597.

Papacharissi, Z. (2010). A Private Sphere: Democracy in a Digital Age. Cambridge, UK: Polity.

Photiou, I.; Maniou, T.; Eteokleous, N., and Ketteni, E. (2017). "Infotainment Journalism in Times of Crisis: A Case Study in the Greek-Cypriot Press". Journal of Media Critiques [JMC], 3(12), pp.157-177. DOI: <10.17349/ jmc117409>.

Photiou, I.; Papadopoulou, L.; Eleftheriadou, A., and Maniou, T.A. (2019). "Visual Infotainment in the Political News". MedieKultur: Journal of Media and Communication Research, 35(66), pp. 075-100.

Pongolini, M.; Lundin, J., and Svensson, L. (2011). "Global Online Meetings in Virtual Teams: From Media Choice to Interaction Negotiation". Proceedings of the 5th International Conference on Communities and Technologies, $\mathrm{pp}$. 108-117. Available at: DOI: <https://dl.acm. org/doi/pdf/10.1145/2103354.2103369>. Accessed 19 April 2020.

Procopio, C. H. and Procopio, S. T. (2007). "Do You Know What It Means To Miss New 
Orleans? Internet Communication, Geographic Community, and Social Capital in Crisis". Journal of Applied Communication Research, 35(1), pp. 67-87.

Romero, E. and Pescosolido, A. (2008). "Humor and Group Effectiveness". Human Relations, 61(3), pp. 395-418.

Stephens, K. K. and Malone, P. (2009). "If the Organizations Won't Give Us Information ...: The Use of Multiple New Media for Crisis Technical Translations and Dialogue". Journal of Public Relations Research, 21(2), pp. 229-239.

Sutton, J.; Palen, L., and Shklovski, I. (2008). "Backchannels on the Front Lines: Emergent Uses of Social Media in the 2007 Southern California Wildfires". In: Fiedrich, F. and Walle, B. van de (eds.). Proceedings of the 5th International ISCRAM Conference. Washington, DC, pp. 1178-1204.

Tchubykalo, E.; Manfredi-Sánchez, J. L., and Sánchez-Giménez, J. A. (2019). "Think Tanks and Political Influence. How Influencer Networks and the Specialization of Power Are Represented on Twitter". Tripodos, 45, pp. 111-131.

Valenzuela, S. (2013). "Unpacking the Use of Social Media for Protest Behavior: The Roles of Information, Opinion Expression, and Activism". American Behavioral Scientist, 57(7), pp. 920-942.

Zúñiga, G. de; Nakwon-Jung, H., and Valenzuela, S. (2012). "Social Media Use for News and Individuals' Social Capital, Civic Engagement and Political Participation". Journal of ComputerMediated Communication, 17(3), pp. 319-336. 
